\title{
Self-fulfilling Chaotic Mistakes: Some Examples and Implications
}

\author{
J. BARKLEY ROSSER, JR.* \\ James Madison University, Harrisonburg, VA 22807, USA
}

(Received 25 October 1998)

\section{INTRODUCTION}

In talks given early in the 1990s, Jean-Michel Grandmont (1998) introduced the concept of the self-fulfilling mistake. This phenomenon can emerge when economic agents cannot distinguish between randomness and determinism, a situation that can occur when the underlying true dynamics are chaotic (Radunskaya, 1994), although such a situation could arise with other forms of complex nonlinear dynamics besides those involving chaotic dynamics. In such a situation, agents may be unable to discern the true dynamics and may adopt simple, boundedly rational "rules of thumb" based on some kind of backward-looking adaptive expectations (Bullard, 1994). For certain kinds of underlying processes, agents may be able to mimic the actual dynamics with such an "incorrect" behavioral rule, an outcome known as a consistent expectations equilibrium (CEE), a concept formalized by
Hommes (1998) as meaning that the two processes have identical means and also autocorrelation coefficients at all leads and lags. Sorger (1998) and Hommes and Sorger (1998) have shown how in some cases agents can learn to converge on such CEEs, or self-filfillingly mistaken behavior. These models all involve discrete dynamics. The first realization that a discrete chaotic dynamic could be mimicked by a simple linear autocorrelation function is due to Bunow and Weiss (1979) and Sakai and Tokumaru (1980), the latter demonstrating the possibility for the case of the asymmetric tent map, a result studied in more depth by Brock and Dechert (1991) and Radunskaya (1994).

Several models have now been studied which can lead to such results, although the full implications of this possibility have not been worked out in all such cases. Among macroeconomic examples are that of Sorger (1998) in which he presents an overlapping generations (OLG) model with a

*E-mail: rosserjb@jmu.edu. 
simple Cobb-Douglas technology and a nonlinear savings function that leads to an asymmetric tent map as the true dynamic adjustment process. Another is a model of a backward-bending supply curve of labor due to Bolle and Neugart (1998). They demonstrate the possibility of chaotic dynamics in this model, but do not fully work out the selffulfilling mistake implications; even though it can be shown that such backward-bending supply curves can lead to such outcomes.

In microeconomics it has long been understood that cobweb adjustment models can generate chaotic dynamics in a broad array of situations (Chiarella, 1988; Hommes, 1991). Cobweb behavior is a species of simple adaptive expectations behavior based on an autocorrelation function of past data, in the simplest case a simple one-period lag autocorrelation function, AR(1) process. Hommes and Sorger (1998) show for the case of a backward-bending supply curve in which the true underlying dynamics are an asymmetric tent map that a simple AR(1) cobweb behavior can mimic the true dynamics in the manner of the self-fulfilling mistake. They also show the possibility of agents learning to believe in chaos by converging on the CEE cobweb dynamic. In turn, Hommes and Rosser (1998) extend this analysis to the case of a renewable resource market, a fishery being the most obvious example. They demonstrate the possibility of a chaotic CEE for this case.

The possibility of such outcomes suggests intriguing implications. On the one hand it mitigates what has been sometimes viewed as the nihilistic implications of chaos theory and complex dynamics more generally in economics. It has long been argued (Grandmont, 1985) that the possibility of chaotic dynamics undermines the possibility of forming rational expectations, expectations that are accurate on average, because of the problem of sensitive dependence on initial conditions in a noisy economic environment. But the possibility of consistent expectations equilibria raises the possibility that agents might well be able to act as if they have rational expectations even when they do not in a chaotic universe. Such a possibility raises hope for optimism about the potential for optimal and stable behavior in markets where such behavior is not at all evident, as in many fisheries.

On the other hand it must be recognized that these results appear to hold only for certain types of true underlying discrete dynamical processes. It is currently unknown and remains a topic for future research just how widespread such cases really are or whether they are really just Lebesgue measure zero in the space of possible true dynamics. If the latter is the case, then these cases may represent interesting examples for contemplation, but cannot be taken seriously as offering hope for overcoming the destructive implications for rational expectations of chaotic dynamics more generally.

After formally presenting the concept of the consistent expectations equilibrium, this paper will present a more detailed outline of the underpinnings of the model of fishery dynamics. Further discussion of implications will conclude this exposition of these examples.

\section{CONSISTENT EXPECTATIONS EQUILIBRIUM}

Let a discrete dynamical system be given by

$$
p_{t}=G\left(p_{t}^{\mathrm{e}}\right)
$$

the left-hand side variable represents the actual value of $p$ in time $t$ while the right-hand side variable entering the function $g$ is the expected value of $p$ in time $t$, which is formed in the previous period, $t-1$. We use $p$ as in the model discussed below the sequence modeled is that of price. The function $G$ may be nonlinear and possibly chaotic or complex in some other form. However the agents form expectations according to a simple boundedly rational rule. Following Hommes and Sorger (1998) we shall let that be a simple one-period linear autoreggressive function, AR(1), of the form

$$
p_{t}^{\mathrm{e}}=\alpha+\beta\left(p_{t-1}-\alpha\right)
$$


The implied actual law of motion is thus given by substituting (2) into (1).

A CEE is then defined as a triple $\left\{\left(p_{t}\right)_{t=0}^{\infty} ; \alpha, \beta\right\}$ such that $\left(p_{t}\right)_{t=0}^{\infty}$ is a sequence of real numbers, $\alpha \in \mathbf{R}, \beta \in[-1,1]$, and:

(a) the sequence satisfies the implied actual law of motion;

(b) the sample average $p^{\wedge}$ equals $\alpha$ and is given by

$$
p^{\wedge}=\lim _{T \rightarrow \infty}(1 / T+1) \sum_{t=0}^{T} p_{t}
$$

(c) for the sample autocorrelation coefficients $\rho_{j}$

(1) if the sequence converges, then $\operatorname{sgn}\left(\rho_{j}\right)=$ $\operatorname{sgn}\left(\beta^{j}\right), j \geq 1$

(2) if the sequence is not convergent, then $\rho_{j}=\beta^{j}, j \geq 1$

with the sample autocorrelation coefficients given by

$$
\begin{aligned}
\rho_{j}= & \lim _{T \rightarrow \infty}\left[(1 / T+1) \sum_{t=0}^{T}\left(p_{t}-p^{\wedge}\right)^{2}\right] /[(1 / T+1) \\
& \left.\times \sum_{t=0}^{T-j}\left(p_{t}-p^{\wedge}\right)\left(p_{t+j}-p^{\wedge}\right)\right] .
\end{aligned}
$$

Thus, a CEE is a sequence and a belief process that generates expectations based on an AR(1) process that is self-fulfilling in terms of sample averages and autocorrelations. The agents have no reason to change their behavior because their beliefs are not generating systematic errors. This definition can be extended to higher-order AR processes.

Furthermore, a CEE can converge to a single point, or to a periodic cycle, or it can be chaotic. A case in which a CEE can be chaotic for such an $\mathrm{AR}(1)$ process of expectations formation is when the true dynamic is an asymmetric tent map (Sakai and Tokumaru, 1980), as shown in Fig. 1. Following Hommes and Sorger (1998), such a case could

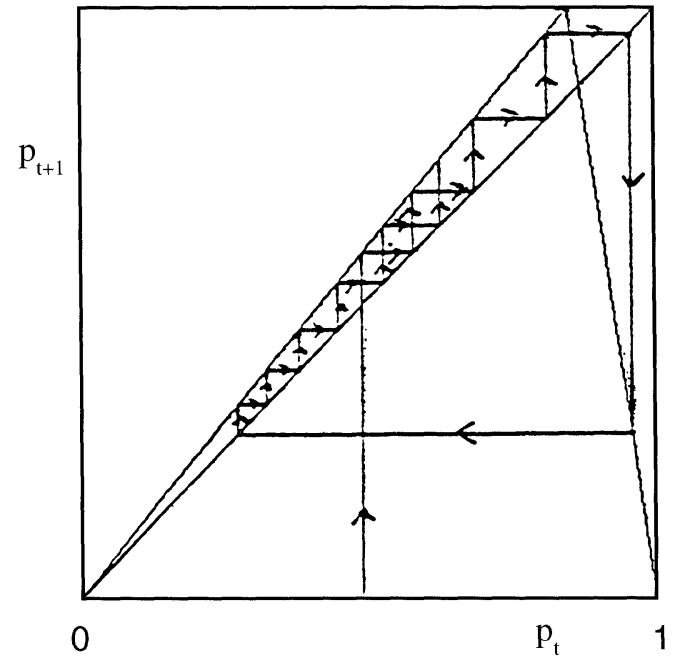

FIGURE 1 Asymmetric tent map chaotic dynamics.

be given for all $p \in[a, b]$ and $\gamma \in[-1,1]$ by

$$
\begin{aligned}
p_{t}= & G\left(\alpha+\beta\left(p_{t-1}-\alpha\right)\right) \\
= & \left\{\begin{array}{c}
\left\{2\left[\alpha+\beta\left(p_{t-1}-\alpha\right)-a\right] /(1+\gamma)\right\}+a \\
\text { if } a \leq \alpha+\beta\left(p_{t-1}-\alpha\right) \leq \\
a+[(1+\gamma) / 2](b-a) \\
\left\{2\left[b-\alpha-\beta\left(p_{t-1}-\alpha\right)\right] /(1-\gamma)\right\}+a \\
\text { if } a+[(1+\gamma) / 2](b-a)< \\
\alpha+\beta\left(p_{t-1}-\alpha\right) \leq b .
\end{array}\right.
\end{aligned}
$$

Such a chaotic CEE is observable if there is a set of initial states of positive Lebesgue measure for which the sequence follows a chaotic attractor.

Even if the agents do not initially select the $\alpha$ and $\beta$ that generate such a chaotic CEE, there can exist positive Lebesgue measure sets of initial values for those for which a simple learning mechanism, such as sample autocorrelation learning, will lead the agent to adjust those values so that they converge on the $\alpha$ and $\beta$ that do generate such a chaotic CEE. Such a process may start out with very regular behavior that then becomes more complex as the system converges on the chaotic implied actual law of motion. This is known as learning to believe in chaos (Hommes, 1998). 


\section{CHAOTIC CONSISTENT EXPECTATIONS EQUILIBRIA IN FISHERY DYNAMICS}

In this section we shall consider the example of dynamics in fisheries to see how such a chaotic CEE can arise in real world cases, following Hommes and Rosser (1998). Fisheries have long presented great difficulties of understanding to both biologists and economists, as well as to policymakers. This has been especially the case as there have been many collapses of fisheries around the world as well as serious disputes between fishers from different countries. Understanding fisheries involves modeling both the biological aspect as well as the economic aspect and integrating the two in a sound manner, a fusion labeled bioeconomics by Colin W. Clark (1990). Clark $(1985,1990)$ emphasizes that the modeling of fishery dynamics is among the most complicated and difficult of all such cases of bioeconomic modeling. As a scientist who has also been involved with advising the Canadian government regarding managing the now-collapsed Grand Banks cod fishery, he is also acutely aware of the policy difficulties involved as well.

A number of special peculiarities arise in the case of fisheries. One, understood since the work of Copes (1970), is that supply curves in fisheries may be backward-bending, one of the few markets where this can happen. ${ }^{* *}$ Copes did not present a rigorous derivation of this result but rather imputed it from the problem of open access that had long been identified as a serious problem aggravating the overharvesting problem in many fisheries (Gordon, 1954). ${ }^{\dagger}$ However Clark (1990) shows that such a backwardbending outcome can occur in an optimally managed fishery without open access, as long as there is a sufficiently high discount rate, a result that will be explicitly derived below. In such cases we already know that chaotic dynamics can arise in fairly simple models with discrete dynamic adjustments. Conklin and Kolberg (1994) have provided a specific model of chaotic dynamics for the Pacific halibut fishery with such a backward-bending supply curve, although without using a CEE framework.

Coming out of much of this previous work are generalizations that Hommes and Rosser (1998) reinforce as well. Chaotic dynamics, and chaotic CEEs in particular, are more likely to happen when there is either open access, high discount rates, or relatively inelastic demand curves, the latter being a result emphasized more broadly in more general nonlinear bioeconomic models by Chavas and Holt (1995). Needless to say, identifying these general problems is far from solving them in the real world.

We shall now lay out a model of an optimal fishery, following Clark (1990), but explicitly solving for certain elements left unsolved in his book. He in turn drew on the classic model of Schaefer (1957) which assumes a logistic function for population dynamics. The presentation below will be in terms of a continuous model, although the simulations by Hommes and Rosser (1998) based on this model are based on a discrete version.

Let

$x=$ population or stock of fish, measured in terms of biomass units;

$r=$ the intrinsic growth rate of the fish population;

$k=$ the ecological carrying capacity for the fishery, maximum possible steady-state level of $x$;

$t=$ time, with the unit being a day in most fishery models;

$h=$ harvest; and

$F(x)=\mathrm{d} x / \mathrm{d} t$ without harvest.

\footnotetext{
** Dávila and Martín-González (1997) show that considerably more complicated patterns of backward-bending supply curves can exist in systems where the fish are in a predator-prey system. Rosser (1991) discusses various models with more complicated interspecies interactions.

${ }^{\dagger}$ Gordon (1954) originally identified the problem of overharvesting of fisheries due to open access with the existence of "common property resources," an identification that was picked up in the large literature on "the tragedy of the commons" (Hardin, 1968). It has since been realized (Ciriacy-Wantrup and Bishop, 1975) that these are distinct issues with the problems arising specifically from open access. Some common property resources have been and continue to be managed in ways so as to limit access, such as the Swiss alpine grazing fields (Netting, 1976) with some observers suggesting revivals of such traditional community methods of common property management to control access (Ostrom, 1990; Bromley, 1991; Rosser, 1995).
} 
The Schaefer (1957) model provides the following relatively simple sustained yield function, ${ }^{\ddagger}$ with sustained yield holding if $h=F(x)$ :

$$
h=F(x)=r x(1-x / k) .
$$

This yield function admits of a level of $x$ at which a maximum sustained yield (MSY) will occur which will be at $x=k / 2$. We note that there has long been a conflict between biologists and economists, with many biologists favoring the MSY level of the population as being the goal of optimal public policy, whereas when economic considerations are added to the biological ones in a combined bioeconomic analysis, it is highly unlikely that the MSY is optimal from the economic standpoint.

We now introduce economic variables including:

$E=$ catch effort, measured in standardized vessel time;

$q=$ catch ability, measured per vessel per day and reflecting technology, and labor and capital;

$c=$ marginal cost of effort, assumed to be a constant;

$p=$ price of the fish per biomass unit;

$\delta=$ discount rate.

Following Gordon (1954) the harvest equation becomes

$$
h(x)=E x .
$$

This implies that total revenue will be $p q E x$. Total cost will equal $c E$, another somewhat simplified equation, given that Clark (1990) has studied cost functions with congestion effects and dynamic models in which capital stock has inertia in the form of the unwillingness of fishers to retire their vessels even when a fishery is obviously being overfished. This latter phenomenon can play an especially important role in the collapse of actual fisheries, but we shall not consider it further here other than to note that such collapses arise from fishing taking place beyond the MSY level.

Gordon (1954) solved for the open access equilibrium in which all positive rents would be fished away by the continuing entry of fishers into the fishery until that point is reached. Such entry behavior can be shown to arise from a certain kind of externality in which the individual fisher perceives his private marginal product to equal the social average product, the amount currently being caught per vessel per day. In effect, the entering fishers do not take into account the effect of their entry on the fishery and so too many of them enter and the fishery is overfished from an economic perspective. This open access equilibrium is now called a bionomic equilibrium and will occur where total revenue equals total cost at

$$
\begin{aligned}
E_{\infty} & =r / q(1-c / p q k) \\
x_{\infty} & =c / p q .
\end{aligned}
$$

The left-hand-side terms have the subscript $\infty$ because this solution is identical to the socially optimal solution to be presented below when the discount rate is infinite, with the discount rate being given by $\delta$. That is the same as saying that the fishers are totally myopic and are paying no attention whatsoever to the future in their decisionmaking. That can be seen intuitively as being essentially what happens in the open access situation where no individual fisher is taking into account the effects of his own actions. If $\delta=0$ then fishers will treat the far distant future as being equally valuable as today, that is they will be very farsighted.

Clark (1990) presents both an optimal control solution and an optimal social utility solution which yield the same result. Here we follow the optimal social utility case, in which we assume that there exists a non-trivial social utility function (Clark, 1990, pp. 138-139), $U(h)$. Let $P(h)$ be the

\footnotetext{
${ }^{\ddagger}$ More complicated yield functions can involve depensation and critical depensation (Clark, 1990; Rosser, 1991). Critical depensation leads to the case where if the population falls below a critical minimum level, the population will catastrophically collapse to zero. Needless to say, this is no longer a sustained yield situation. This will not happen with the Schaefer logistic yield function.
} 
demand function ( $h$ is the sustained yield quantity), then we get

$$
U(h)=\int P(h) \mathrm{d} h,
$$

which is the usual consumer's surplus equation. Net social utility is maximized by

$$
\max J_{\text {soc }}\{h\}=\int_{0}^{\infty} \mathrm{e}^{-\delta t}[U(h)-c(x, h)] \mathrm{d} t
$$

subject to $x(t) \geq 0, h(t) \geq 0, c(x, h)=c(x) h$, and

$$
\mathrm{d} x / \mathrm{d} t=F(x)-h(t), \quad x(0)=x_{0} .
$$

The resulting Hamiltionian is given by

$$
H=\mathrm{e}^{-\delta t}[U(h)-c(x) h]+\lambda(t)[F(x)-h] .
$$

Pontryagin's Maximum Principle gives

$$
\partial H / \partial h=\mathrm{e}^{-\delta t}\left[U^{\prime}(h)-c(x)\right]-\lambda(t)=0,
$$

or

$$
\lambda(t)=\mathrm{e}^{-\delta t}\left[U^{\prime}(h)-c(x)\right],
$$

which is strictly true only if $h>0$, and

$$
\begin{aligned}
\mathrm{d} h / \mathrm{d} t= & 1 / U^{\prime \prime}(h)\left\{\left[\delta-F^{\prime}(x)\right]\left[U^{\prime}(h)-c(x)\right]\right. \\
& \left.+c^{\prime}(x) F(x)\right\} .
\end{aligned}
$$

Assuming that $U^{\prime}=P$ and setting $\mathrm{d} x / \mathrm{d} t=\mathrm{d} h / \mathrm{d} t=0$ gives

$$
F^{\prime}(x)-\left[c^{\prime}(x) F(x)\right] /[P(h)-c(x)]=\delta,
$$

or

$$
P(h)=c(x)-\left[c^{\prime}(x) F(x)\right] /\left[\delta-F^{\prime}(x)\right] .
$$

Combining this with $h=F(x)$ will give us our basic combined discounted supply and demand system, although we have not yet gotten the supply curve

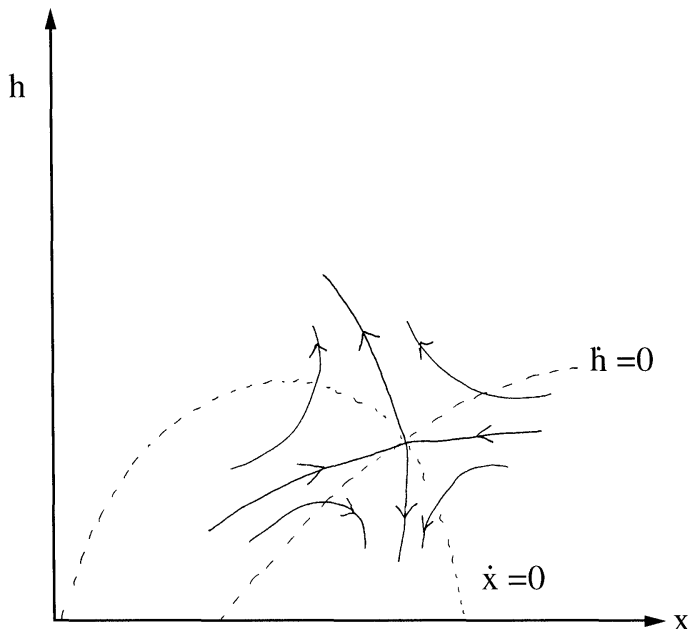

FIGURE 2 Harvest-Biomass phase diagram.

directly as a function of quantity $(h)$. Figure 2 shows a phase diagram in the biomass $(x)$ and harvest $(h)$ space for this system (Clark, 1990, p. 143).

From Hommes and Rosser (1998) we have the rest of this derivation to get the form we need. Assuming the Schaefer sustained yield equation from above as well as from (9) that $c(x)=c / q x$, we get

$$
\begin{aligned}
c^{\prime}(x) & =-c / q x^{2} \\
F^{\prime}(x) & =r-2 r x / k .
\end{aligned}
$$

Substituting these into (18) and rearranging gives

$$
P=c\{(1 / q x)+r(1 / q x-1 / q k) /(\delta-r+2 r x / k) .
$$

We need $x$ as a function of $h$ which can be gotten by solving the quadratic Schaefer equation (6):

$$
x=k / 2 \pm(k h / r)^{1 / 2} .
$$

Plugging this into (21) gives us our supply function

$$
\begin{aligned}
p=c\{ & {\left[1 / q\left(k / 2+(k h / r)^{1 / 2}\right)\right] } \\
+ & r\left[\left(1 / q\left(k / 2+(k h / r)^{1 / 2}\right)\right)-1 / q k\right] \\
& \left./\left[\delta-2(r h / k)^{1 / 2}\right]\right\} .
\end{aligned}
$$




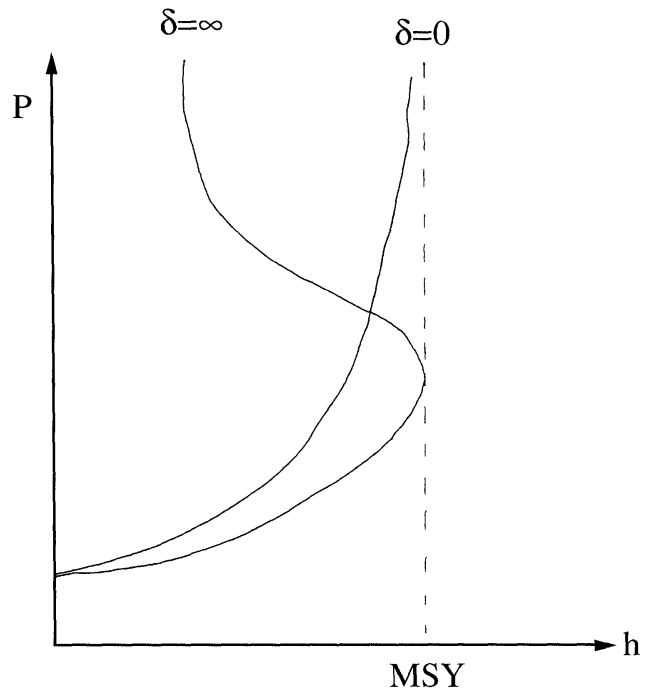

FIGURE 3 Supply curves with different discount rates.

Figure 3 shows how this supply function varies with $\delta$, with the supply curve being upward-sloping throughout when $\delta=0$, that is when society treats the far distant future as equally valuable as today, or in the case of the equivalent model based on fishers' behavior derived from their optimal control problem, when the fishers have such a view. The most backwardly bent supply curve corresponds with the totally myopic case of $\delta=\infty$, which corresponds to the open access bionomic equilibrium case studied by Gordon (1954) and which is associated with overfishing behavior. We note that the supply curve bends backwards quite quickly at values of the discount rate in the single digits that are empirically and socially meaningful, in contrast with the kinds of discount rates that are necessary to generate chaotic dynamics in golden rule neoclassical growth models (Nishimura and Yano, 1996; Montrucchio and Sorger, 1996; Mitra, 1998).

The upper right portion of Fig. 4 shows the case of the backward-bending supply curve with a sufficiently inelastic demand curve that then shifts so that there are multiple equilibria even for the

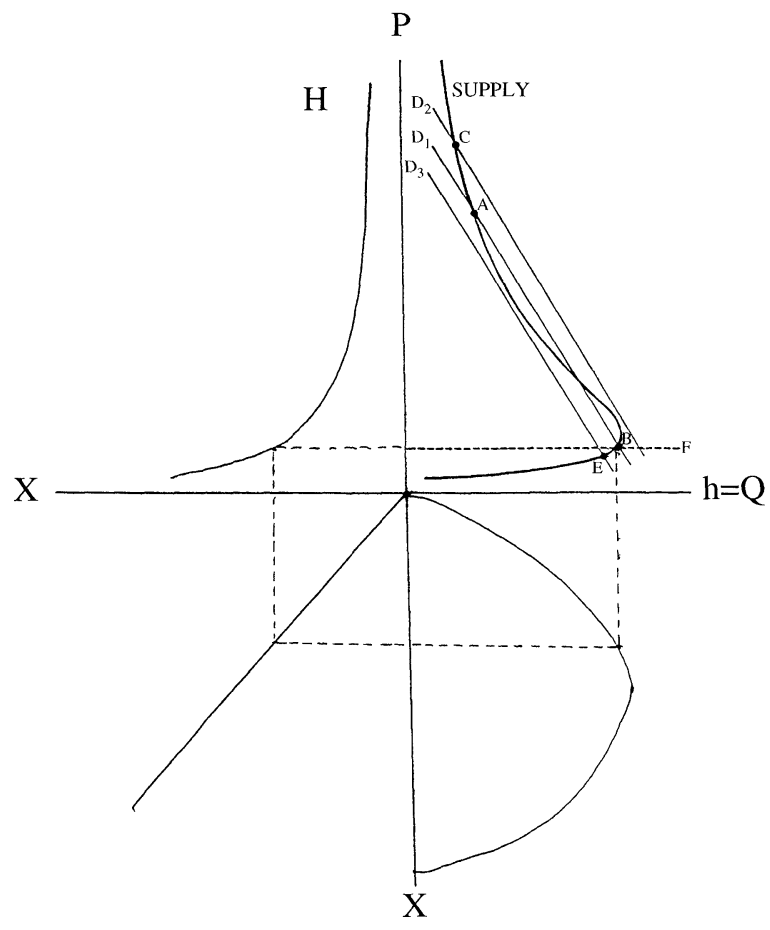

FIGURE 4 Bioeconomic equilibria: Backward-bending supply and shifting demand.

static case. ${ }^{\S}$ This shows the original argument of Copes (1970) who argued that in such a situation, increasing demand could lead to a collapse of a fishery as the equilibrium jumps discontinuously from $b$ to $c$. Such a result can be modeled by using catastrophe theory and was done so for the collapse of the Antarctic fin and blue whale stocks (Jones and Walters, 1976), the latter falling from over 150,000 to less than 1000 within the space of a few years during the 1960s (Clark, 1985, p. 6). Clark (1985) provides a comprehensive (and lengthy) list of fisheries that have collapsed around the world, although, as we have already noted, a variety of other factors including capital stock inertia have been involved in these tragedies.

Figure 4 shows the combined system with the supply and demand curves in the upper-right-hand corner, the Schaefer yield function in the lowerright-hand corner, and Eq. (18), price as a function

${ }^{\S}$ Conklin and Kolberg (1994) show that it is not necessary to have such a degree of inelasticity of demand that there are multiple equilbria in order for chaotic dynamics to occur, as long as there is a backward-bending supply curve. 
of the stock of fish, in the upper-left-hand corner. The link between the supply curve and the yield curve can be seen by solving for price at the MSY point. Given that $x=k / 2$ there, we know that $(k h / r)^{1 / 2}=0$ at that value. Thus at MSY we have a price of

$$
p=c[(c+2 \delta) / q k \delta] .
$$

In Hommes and Rosser (1998) parameter values taken from Clark (1985) for several specific fisheries are used for cases with backward-bending supply curves in a discrete system with a price expectations adjustment mechanism similar to that in Hommes and Sorger (1998) as presented in the previous section of this paper. Simulations of this system show that observable chaotic CEEs exist for substantial ranges of parameter values and that "learning to believe in chaos" also exists even with stochastic noise.

One major difference between these systems and those in Hommes and Sorger (1998) is that Hommes and Rosser (1998) find chaotic CEEs emerging even for cases that do not have kinks in the curves determining the underlying law of motion. In Hommes and Sorger (1998), as in the other studies cited here that have come up with selffulfilling chaotic mistake behavior, the underlying law of motion is given by something like an asymmetric tent map that has a kink in it. But Hommes and Rosser (1998) find observable chaotic CEE behavior in a system drawn from the nonkinked but backward-bending supply curve system shown above. This shows an extension of the chaotic CEE result to a broader category of functional types, but certainly leaves unresolved the question of just how broad are the categories of functions for which such phenomena can be observed.

\section{SUMMARY AND CONCLUSIONS}

We have seen that there are a growing number of examples of systems where self-fulfilling chaotic mistakes can occur in the form of chaotic CEE with the possibility of convergence through learning to those equilibria through simple learning processes, the phenomenon of learning to believe in chaos. Such cases include models where the underlying dynamics are determined by asymmetric tent maps as with the OLG macroeconomic model of Sorger (1998) and the generic price adjustment model of Hommes and Sorger (1998). We have seen presented in more detail in this paper a model of fishery dynamics that has been used by Hommes and Rosser (1998) to show such phenomena for realistic parameter values even for systems where the underlying dynamics are given by functions that do not have kinks of the sort found in the asymmetric tent map. This suggests that the backward-bending macroeconomic labor supply curve model of Bolle and Neugart (1998) could be adapted to generate such self-fulfilling chaotic mistakes within an appropriate discrete dynamical framework.

With regard to the specific issues raised by consideration of the fishery dynamics model several points are in order. One is that this modeling effort certainly reinforces much that has already been known: that chaotic or irregular dynamics are more likely as myopia is greater, or as there is a lack of control over access for which the solution resembles the optimal solution with total myopia. This suggests that efforts to make the markets and fishers take a longer term perspective and also to encourage systems to control access should be encouraged, either by reassigning or enforcing property rights, although we have no specific new proposals regarding these difficult and complicated issues.

However the results in this paper do suggest at least one element of optimism that may not have been known by analysts of these problems previously. The implications of the possible existence of observable chaotic CEEs in fisheries suggests that in a world of underlying chaotic dynamics, fishers may be able to mimic the behavior implied by accurate expectations by fairly simple, boundedly rational rules of adaptation. More particularly, in contrast with the catastrophic 
results arising from some models and situations, it should be kept in mind that chaotic dynamics remain bounded. Thus, if a group of fishers fishing a fishery are actually able to successfully follow an underlying truly chaotic dynamic, even if by doing so through learning to believe in a self-fulfilling chaotic mistake, the results of their doing so will not lead to the collapse of that fishery, which is certainly a desideratum.

\section{Acknowledgments}

The author wishes to thank William A. Brock, Jean-Paul Chavas, Colin W. Clark, Nancy Dávila, Jean-Michel Grandmont, Cars H. Hommes, Michael Kopel, Scott R. Milliman, Michael Neugart, and Tönu Puu for either advice or useful materials. None are responsible for any errors in this paper.

\section{References}

Bolle, M. and Neugart, M. (1998). Complex dynamics in a model with backward bending labour supply. Mimeo. Free University of Berlin.

Brock, W.A. and Dechert, W.D. (1991). Non-linear dynamical systems: Instability and chaos in economics. In Handbook of Mathematical Economics, Vol. IV (W. Hildenbrand and H. Sonnenschein, Eds.). North-Holland, Amsterdam, pp. 2209-2235

Bromley, D.W. (1991). Environment and Economy: Property Rights and Public Policy. Basil Blackwell, Oxford.

Bullard, J. (1994). Learning equilibria. Journal of Economic Theory 64, 468-485.

Bunow, B. and Weiss, G.H. (1979). How chaotic is chaos? Chaotic and other noisy dynamics in the frequency domain. Mathematical Biosciences 47, 221-237.

Chavas, J.-P. and Holt, M. (1995). Nonlinear dynamics and economic instability: The optimal management of a biological population. Journal of Agricultural and Resource Economics 20, 231-246.

Chiarella, C. (1988). The cobweb model: Its instability and the onset of chaos. Economic Modelling 5, 377-384.

Ciriacy-Wantrup, S.V. and Bishop, R.C. (1975). "Common property" as a concept in natural resources policy. Natural Resources Journal 15, 713-727.

Clark, C.W. (1985). Bioeconomic Modelling and Fisheries Management. Wiley-Interscience, New York.

Clark, C.W. (1990). Mathematical Bioeconomics: The Optimal Management of Renewable Resources, 2nd edn. Wiley-Interscience, New York
Conklin, J. and Kolberg, W. (1994). Chaos for the halibut? Marine Resource Economics 9, 153-182.

Copes, P. (1970). The backward-bending supply curve of the fishing industry. Scottish Journal of Political Economy 17, $69-77$.

Dávila, N. and Martin-González, J.M. (1997). Supply-demand curves and optimal harvesting in a multi-species fishery. Mimeo. University of Las Palmas de Gran Canario.

Gordon, H.S. (1954). The economic theory of a common property resource: The fishery. Journal of Political Economy 64, 124-142.

Grandmont, J.-M. (1985). On endogenous competitive business cycles. Econometrica 53, 995-1045.

Grandmont, J.-M. (1998). Expectations formation and stability in large socioeconomic systems. Econometrica 66, 741-781.

Hardin, G. (1968). The tragedy of the commons. Science 162, $1243-1248$.

Hommes, C.H. (1991). Chaotic Dynamics in Economic Models: Some Simple Cases. Wolters- Noordhoff, Groningen.

Hommes, C.H. (1998). On the consistency of backward-looking expectations: The case of the cobweb. Journal of Economic Behavior and Organization 33, 333-362.

Hommes, C.H. and Sorger, G. (1998). Consistent expectations equilibria. Macroeconomic Dynamics 2, 287-321.

Hommes, C.H. and Rosser, Jr., J.B. (1998). Consistent expectations equilibria and complex dynamics in renewable resource markets. Mimeo. University of Amsterdam and James Madison University.

Jones, D.D. and Walters, C.J. (1976). Catastrophe theory and fisheries regulation. Journal of the Fisheries Research Board of Canada 33, 2829-2833.

Mitra, T. (1998). On the relationship between discounting and complicated behavior in dynamic optimization models. Journal of Economic Behavior and Organization 33, 421-434.

Montrucchio, L. and Sorger, G. (1996). Topological entropy of policy functions in concave dynamic optimization models. Journal of Mathematical Economics 25, 181-194.

Netting, R. (1976). What alpine peasants have in common: Observations on communal tenure in a Swiss village. Human Ecology 4, 135-146.

Nishimura, K. and Yano, M. (1996). On the least upper bound of discount factors that are compatible with optimal period-three cycles. Journal of Economic Theory 69, 306-333.

Ostrom, E. (1990). Governing the Commons. Cambridge University Press, Cambridge, UK.

Radunskaya, A. (1994). Comparing random and deterministic time series. Economic Theory 4, 765-776.

Rosser, Jr., J.B. (1991). From Catastrophe to Chaos: A General Theory of Economic Discontinuities. Kluwer Academic Publishers, Boston/Dordrecht.

Rosser, Jr., J.B. (1995). Systemic crises in hierarchical ecological economies. Land Economics 71, 163-172.

Sakai, H. and Tokumaru, H. (1980). Autocorrelations of a certain chaos. IEEE Transactions on Acoustics, Speech and Signal Processing 28, 588-590.

Schaefer, M.B. (1957). Some considerations of population dynamics and economics in relation to the management of marine fisheries. Journal of the Fisheries Research Board of Canada 14, 669-681.

Sorger, G. (1998). Imperfect foresight and chaos: An example of a self-fulfilling mistake. Journal of Economic Behavior and Organization 33, 363-383. 


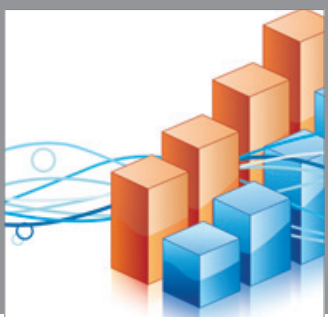

Advances in

Operations Research

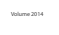

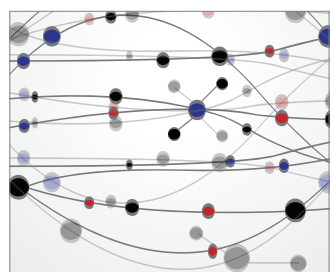

\section{The Scientific} World Journal
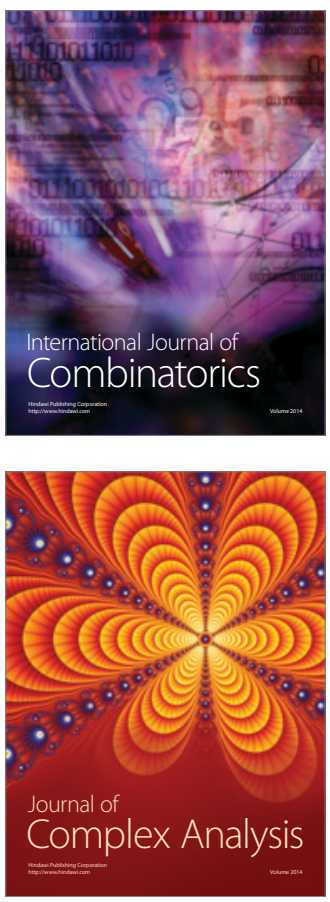

International Journal of

Mathematics and

Mathematical

Sciences
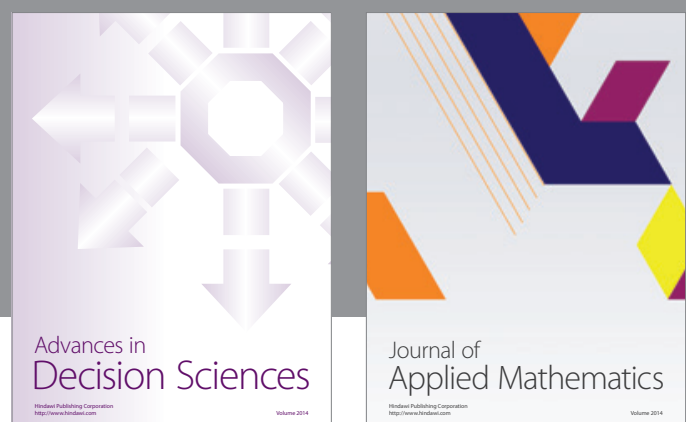

Journal of

Applied Mathematics
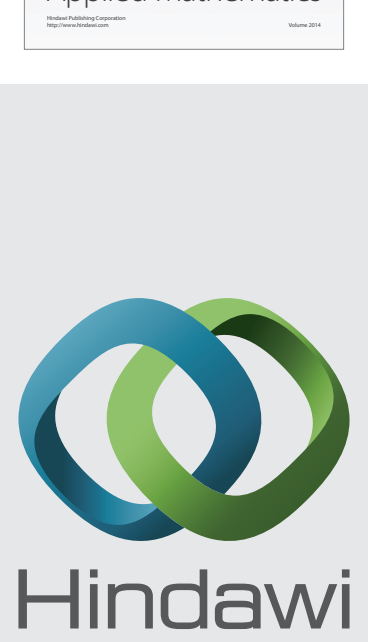

Submit your manuscripts at http://www.hindawi.com
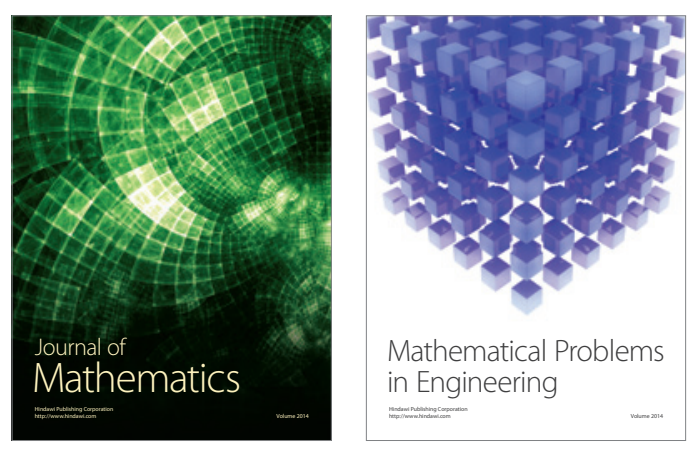

Mathematical Problems in Engineering
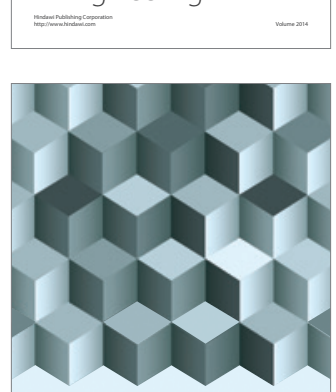

Journal of

Function Spaces
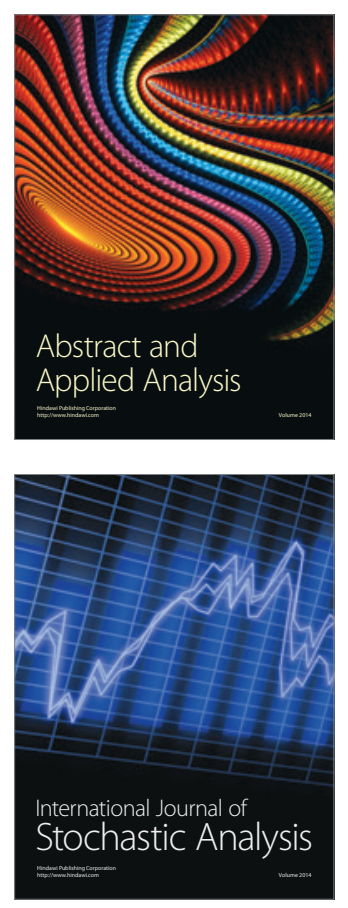

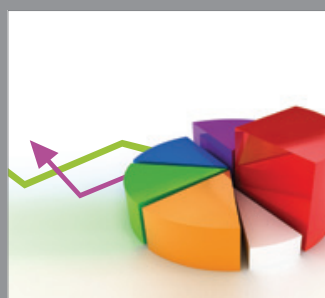

ournal of

Probability and Statistics

Promensencen
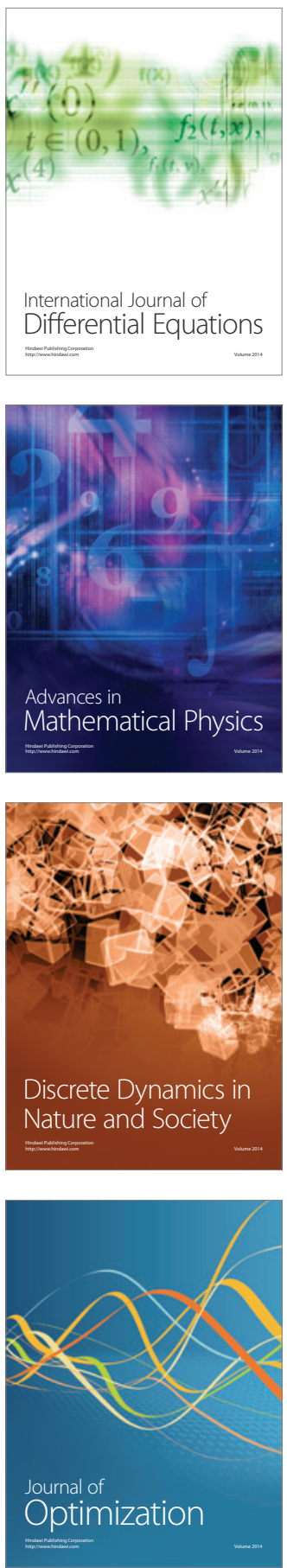